\title{
Multi-Stakeholder Partnerships (MSPs) for Health Service Delivery in Ethiopia
}

\author{
Hiwot Amare
}

Phd Candidate, KU Leuven Public Governance Institute

\begin{abstract}
The past few decades have witnessed the integration of non-state actors in public service delivery. Partnerships as a form of governance involve state and non-state actors in public policy formulation and implementation. The widespread poverty and severe health problems in Ethiopia demand an increasing role of a wide range of actors outside of the state. In the past few years, the Ethiopian government has been actively seeking collaborative arrangements for health service delivery that are aimed at ensuring access to basic and quality health service delivery. The paper will focus on studying multi-stakeholder partnerships (MSPS) for health service delivery as a form of governance, hence we focus on the internal dynamics of MSPS for health service delivery and provide an understanding of state and non-state interaction in these governance networks. The case analysis is based on a specific MSP for health service delivery at the local level.
\end{abstract}

\section{Keywords}

Network Governance, Public Health, NGOs

\section{Introduction}

The challenges facing communities and countries in the twenty-first century are sufficiently complex in scope and scale as to require the involvement of a range of actors with complementary perspectives, expertise, and resources (Sullivan \& Skelcher, 2002). Therefore, governments in many parts of the world are becoming more collaborative, open, and transparent through the inclusion of societal actors in devising solutions to society's challenges (Peters, 2010). Most of these developments followed the horizontal shifts in state power and control that occurred from public to private and civil society actors and agencies (Pierre \& Peters, 2000). In the context of horizontal coordination, agencies at different levels of government structure increasingly engage in partnerships with civil society actors; these partnerships present a new way of organizing collective action. Partnerships include, among others, NGO-government, donor-government, and public-community.

Although the need to engage in collaborative efforts between state and non-state actors might not be a new thing in the literature (Cammett \& Maclean, 2014), it has especially taken a particular form since the end of the 1980s following the reforms in public administration. The global resurgence of the partnership notion has been attached to a more general trend from government to governance, which signifies the development of new relationships between the public and non-public sectors (Kjaer, 2004; Rhodes, 1994; Salamon, 2002; Stoker, 1998). The concept of partnership emerged as a new governance scheme that is suitable and necessary to address complex social problems (Benner et al., 2004; Johnston, 2015; Lowndes \& Skelcher, 1998; Osborne, 2000; Sørensen \& Torfing, 2005; Sullivan \& Skelcher, 2002; Teisman and Klijn, 2002). Partnerships such as Multi-Stakeholder Partnerships (MSP) are globally promoted as more effective forms of collaborative governance as they are more collaborative, transparent, and inclusive than the traditional forms of governance (Bäckstrand, 2006; Banerjee et al., 2020; Hemmati, 2002). MSPs are horizontally organized, with a greater potential to stimulate the participation of societal actors in open and flexible settings and deliver improved public services. MSPs can be seen as an example of network governance that are collaborative governing schemes in contrast to the traditional hierarchical forms of governance.

In the context of new governance approaches, networks emerge as a major form of social coordination. Network governance was created in response to increasingly complex and dynamic societal challenges that 
require innovative and flexible solutions (Klijn \& Koppenjan, 2016; Larsoon, 2019). Network governance is generally seen as important because the approach can bring a wide range of actors with their respective resources and expertise that enable innovative solutions for complex issues (Head, 2008; Larsson, 2019; Sørensen \& Torfing, 2005), such as complex service delivery initiatives that involve more than one partner (Klijin, 2010). Importantly, collaborative networks may also be helpful in enhancing deliberation and improve both flexibility and responsiveness in providing public services (Head, 2008).

The increasing importance of network governance in the process of societal governance demands further examinations of collaborative networks such as MSPs in a different national context where the political and administrative system is different from the western society. There is strong evidence that modern societies are moving towards a balanced position which emphasizes networked consultation and collaboration with the community and NGO sectors (Head, 2008). Though most of the literature on network governance is focused on North America or Western Europe, there is no or little evidence regarding how network governance works in developing countries (Maes et al., 2018; Moloney, 2013). As such, understanding the opportunities and limits of network-based governance through a careful analysis of the operation and outcomes of networks in a different contexts can have both theoretical and practical importance. In particular, such an analysis helps to determine the relevance of the governance and related flagship concepts and improve their applicability.

The main objective of this study is to investigate how MSPs as network governance function in Ethiopia. The study is based on an empirical study of collaborative governance network that aim to provide health services at the local level in Ethiopia. Ethiopia is a developing country where a large proportion of its population lacks access to basic public services such as health services. Despite incomplete democratic decentralization, the health care system attracts a number of international and local NGOs and other societal actors that form collaborations with public agencies. This study, therefore, examines an empirical case of a collaborative governance network that aims to provide health services at the local level in Ethiopia. The main research question addressed in this paper is: how do MSPs organized for health delivery work in Ethiopia?

This paper is divided into four sections. The first section provides an overview of governance literature, with a special focus on network governance. The paper then develops a theoretical framework by drawing elements from network governance approach, which later used to analyze the overall functioning of MSP. The second section provides a methodology used in collecting and analyzing the data. The third section of the paper provides empirical evidence, based on a single case study of a collaborative project for health service delivery in the North Shewa Zone of Ethiopia. The final section provides the key findings and conclusions of the study.

\section{Theoretical Framework}

This part of the paper provides a brief conceptualization of governance based on literature. It then explores the specific concept of network governance. It especially helps incorporating the idea of state and non-state actors working within networks to deliver public services.

\section{Concept of governance}

In dealing with governance literature two things become apparent. First, there is a mix-up of the terms government and governance and different arguments have been made that try to clear this confusion. For instance, Stoker (1998, p. 17) depicts government as "the formal and institutional processes which operate at the level of the nation state to maintain public order and facilitate collective action.” By contrast, to Rhodes (1996, pp. 1-2), governance is seen as a "new process of governing, or a changed condition of ordered rule; or the new method by which society is governed." Efforts have been done to conceptualize governance as a topic far broader than government (Stoker, 1998; Rhodes, 1996; Rosenau 1992). Government occurs when the formal and legally derived authority of the state regime takes the responsibility to execute activities, while governance relates to the creation 
and implementation of activities through the network of private and public actors, regardless of their formal authority and power (Grote \& Gbikpi, 2002; Rosenau, 1992).

Second, the term governance is used in a variety of ways in the public administration literature; governance usually refers to public sector reforms involving privatization, public enterprises, contracting out, quasi-markets, contract steering, local partnerships, user boards, etc. (Sørensen \& Torfing, 2005). In his widely cited book Understanding Governance, Rhodes (1997) distinguishes six uses of the term governance: Governance as the minimal state; Governance as corporate governance; Governance as the new public management; Governance as "good governance;" Governance as a socio-cybernetic system; Governance as self-organizing networks. Building on the work of Rhodes, Klijn (2008) also stressed that four major definitions dominate the literature. His overview of governance covered governance as good governance or as corporate governance, governance as New Public Management (NPM), governance as multilevel governance or inter-governmental relations, and governance as network governance (self-steering or non-self-steering).

Although the above definitions represent different conceptions of governance, they have something that unites them. All of them focus on the process of governing rather than what the government can do with its formal and authoritative power structure. This is in line with the notion that governments are changing the way they govern society by focusing on the process that can best achieve outcomes rather than concentrating on centralized power (Klijn, 2008). As is widely acknowledged, the shift from government to governance entails the formulation and implementation of public policy by a great number of formal and informal institutions (Noor et al., 2010), instead of "sovereign political institutions that allegedly govern society top-down through enforceable laws and bureaucratic regulations" (Sørensen \& Torfing, 2005, p. 199). Stoker (1998) suggests that among the various interpretations of the term, there is a "baseline agreement that governance refers to the development of governing styles in which boundaries between and within public and private sectors have become blurred" (p. 17). Therefore, this study will focus on interpretations that relate to the shift in the mode of governing towards the involvement of non-public actors (Klijn, 2008; Rhodes, 1997; Salamon. 2002;). We thus will use the term governance to describe "the totality of interactions, in which government, other public bodies, private sector and civil society participate, aiming at solving societal problems or creating societal opportunities” (Meuleman, 2008, p. 11).

Although there is a common understanding that the basic logic of governance in different forms has become ever more widely spread both in practice and academic discourse, in its reality, a governance argument may not be viable in all political systems (Peters, 2010). A major argument of this paper is that to enhance the theoretical value of the concept of governance one must understand how governance networks involving public and nonpublic actors operate in different political and administrative systems.

\section{Network governance as a framework for analysis}

Since the 1990s a vast amount of literature has been devoted to the development of network governance, including work by Klijn, (1996, 2008); Klijn \& Koppenjan, (2000); Kooiman (2001, 2003); Pierre (2000); Rhodes (1994, 1997, 2000); and Sørensen and Torfing (2007). Much of it has started from the observation that alternative analytical models of governance, in which a multitude of public and private actors integrate in order to govern society, have emerged in an effort to address the new complex and challenging societal issues (Klijn \& Koppenjan, 2016; Sorenson \& Torfing, 2005; Torfing \&Ansell, 2017). In this approach, governance takes place mainly within the fluid network of public and non-public actors, which sees no difference between governance and network governance. The concepts appear to be interrelated, with the notion of network governance offering a perspective on the role of horizontal networks in the process of societal governance, which is also basically similar to the governance orientation (Sorenson \& Torfing, 2005). Hence, examining the variation in the operation of network governance can help in advancing our understanding of the nature and consequences of the shift to governance (Menahem \& Stein, 2012).

Although the scholarly discussion on network governance remains highly fragmented in terms of theories, methods, and empirical data (Lewis, 2011; Maes et al., 2018), several attempts have been made to develop coherent 
definitions (Jones et al., 1997; Kickert et al., 1997; Rhodes, 1997; Sørensen \& Torfing, 2007). For instance, Jones et al. (1997) provide definitions that mainly focus on industrial firms and their interaction with other stakeholders; "Network governance involves a select, persistent, and structured set of autonomous firms (as well as nonprofit agencies) engaged in creating products or services based on implicit and open-ended contracts to adapt to environmental contingencies and to coordinate and safeguard exchanges" (1997; p. .914). Rhodes provides a definition that complexly equates governance with network governance and he maintains that "governance refers to self-organizing inter-organizational networks characterized by interdependence, resource exchange, rule of the game and significant autonomy from the state" (Rhodes, 1997, p. 15). The depiction of complex interaction among actors in networks as organizing concept calls for others to see network governance from a management perspective. As the major proponent of this perspective, Kickert et al. (1997) defined network governance as "the 'management' of complex networks, consisting of many different actors from the national, regional and local government, from political groups and from societal groups (pressure, action and interest groups, societal institutions, private and business organizations)" (p. 735). Like most definitions of network governance, it acknowledges the presence of various actors and their complex interaction, but it focuses on the process of managing the complex network. Basic feature common to the above descriptions of network include that they are based on relatively stable patterns of relation between dependent actors within which interaction takes place (Klijn et al., 1995). Consecutively, many describe networks as (more or less) stable patterns of social relations between interdependent actors, which take shape around policy problems and/or policy programs (Kickert et al., 1997; Klijn \& Koppenjan, 2000; Klijn \& Teisman, 1991).

In general, the definition of network governance circulates around the interaction of various actors in the society aimed at policy making and implementation. In line with this, I found Sørensen and Torfing's (2005, pp. 203) definition of network governance most suitable and coherent in the context of this research because it captures most of the features commonly ascribed to networks governance as well as the divergent interpretations of the concept.

They define network governance as:

- A relatively stable horizontal articulation of interdependent, but operationally autonomous actors;

- Who interact through negotiations;

- Which take place within a regulative, normative, cognitive and imaginary framework;

- That to a certain extent is self-regulating; and

- Which contributes to the production of public purpose within or across particular policy areas.

First and foremost, the concept of governance network revolves around a variety of actors and their relations. Governance networks articulate various actors and these actors are from public and private (for profit and nonprofit) sectors. These actors are tied to one another by dependency relations (Kickert et al., 1997; Mandell, 2001; Rhodes, 1997; Scharpf, 1997). Perri et al. (2002) also stipulate governance network as the collaborative relationship between actors from the public, private, and third sectors. A key element for these relationships of actors to arise and to continue to exist is interdependency (Klijn et al., 1995). Actors in networks are thus expected to be dependent on one another while they function as autonomous as they can. According to Sørensen and Torfing (2007), "interdependencies in a network originate from the fragmentation of resources among actors." This implies that actors need each other's resources to achieve their goals. Thus, owning to this dependence actors seek collaboration with each other (Benson, 1982; Rhodes, 1988; Scharpf, 1978). Therefore, "the actors that are included in a particular governance network must demonstrate that they have a stake in the issues at hand and/or that they can contribute resources and competences of a certain value to the other actors" (Sørensen \& Torfing, 2007). This implies that interdependency emerges not only because of resources; it might also flourish (even if no resources are available) because of having a stake.

Second, actors in a network interact through negotiation. Governance networks provide a new and unique mechanism for governing society which is called a negotiation rationality. In network governance, actors 
negotiate common decisions on problem definitions and ways to solve problems, while their compliance with these decisions is based on trust that other actors will also contribute and feel an obligation to contribute to the achievement of common goals. Governance networks tend to develop their own logic of appropriateness that regulates the process of negotiation, the formation of consensus, and the attempt to resolve conflicts (March \& Olsen, 1995; Mayntz, 1991).

Third, the interaction of actors takes place more or less within institutional frameworks. These institutional frameworks can be seen as patterns of social relations (interactions, power relations. etc.) and patterns of rules (Klijn et al., 2012). Interdependencies between actors and the resulting interaction create a pattern of relations that is relatively stable and dense. It is also framed by the rules of conduct that emerge as the interaction evolves. The network literature tends to describe this relation pattern in terms of the regularity of communication and interactions (Kickert et al., 1997).

The institutionalized framework has a regulative aspect in the sense that it provides rules, roles and procedures; a normative aspect in the sense that it conveys norms, values and standards; a cognitive element in the sense that it generates codes, concepts and specialized knowledge; and an imaginary aspect in the sense that it produces identities, ideologies, common hopes and visions. (Sørensen \&Torfing, 2007).

Fourth, it is expected at some level that a network of actors is self-regulating. Self-regulating can mean that networks, as one type of structure of relationship, are not part of a hierarchical chain of command and do not submit themselves to the laws of the market (Scharpf, 1994). Rather they are expected to function on the basis of their own ideas, resources, and capabilities while they are embedded within the institutional framework that is adjusted through actors' regular interaction and negotiation (Sørensen \& Torfing, 2007). Thus, self-regulating is about how they are detached from a hierarchal chain of command and from market structures. However, "networks operate in some kind of environment that needs to be considered, since it both facilitates and constrains its capacity for self-regulation" (Sørensen \& Torfing, 2007, p. 204). Especially, state actors may intentionally or unintentionally attempt to change the horizontal network governance to hierarchical rule. Scharpf (1994, p. 41) also gives the extreme argument by insisting that network governance always takes places "in the shadow of hierarchy." If public authorities attempt to regulate self-regulating networks, there is a greater chance that networks can change to a hierarchal order taking up bureaucratic, hierarchical arrangements.

Fifth, governance networks contribute to the production of public purpose within a certain area (Marsh, 1998) or, taking into account wicked problems as challenges in society, across policy areas. Public purpose is an expression of visions, understandings, values, and policies that are valid for and directed towards the public. Thus, the network actors are engaged in political negotiations about how to identify and solve emerging policy problems or exploit new opportunities (Sørensen \& Torfing, 2007). Networks that do not contribute to the production of public purpose in this broad sense cannot be counted as governance networks. Public purpose can also be used to express efforts by networks directed to policy implementation in the form of service delivery.

\section{The critical view on network governance guiding this research}

In this section, the discussion on network governance is summarized and critically reflected upon in order to contextualize it in relation to the focus of the research. First, networks here are proposed as specific coordination mechanisms through which governance takes place. We start with the argument that a network is a governance mode next to hierarchy and market, as governance network theorists claim that governance networks are a distinctive mechanism of governance providing an alternative to the state and markets. Although some see networks as the defining feature of governance, others have distinguished bureaucratic hierarchies, networks, and markets as different governance modes. We argue that governance can indeed rely on hierarchy, market, and network; but if governance is used to describe the horizontal interdependent relationship between various actors, it implies networks.

Secondly, the defining characteristics of network arrangements can be outlined as interdependency among various actors' negotiation, an institutionalized relationship, capacity to self-regulate, and production of a public 
purpose. If the partnership of actors is regarded as a descriptor of network phenomena, the above characterization can be used as a symbol for the interaction of various actors engaged in partnership arrangements. Therefore, MSPs are here analyzed from a network governance perspective, with a focus on how the different state and nonstate actors collaborate for health service delivery. We thus conceptualize MSPs as networks formed by the collaboration of state actors and non-state actors for delivering health services. Therefore, the analysis in the study focuses on the set of actors involved in service delivery and the relations and resource exchanges in which they are involved.

We set forth the following propositions derived from network governance theory (Sørensen and Torfing, 2005, p. 9):

- MSPs organized for health service are characterized by a relatively stable horizontal articulation of interdependent, but with operationally autonomous actors;

- Actors in MSPs interact through negotiations;

- MSPs as a network of actors take place within a relatively institutionalized framework that is created by interaction of actors;

- MSPs are characterized as self-regulating within limits set by external agencies especially state actors; and

- MSPs as network of actors contribute to the production of public purpose.

Because the above listed propositions are derived from network governance theory, they help in answering the research question. We assume that these propositions are practically present in Ethiopia, but their limited practical presence doesn't imply the total absence of network governance. However, it can only entail that the Ethiopian MSP, as could be true in other cases, is unique to itself in a way that doesn't totally contradict the basic concept of network governance. In short, these propositions propose an ideal-type that can be used for analytical reasons but that thus is not necessarily completely identical to practice.

\section{Governance in Ethiopian health sector context}

Ethiopia, like most developing countries, is struggling with limited resources to meet the basic health needs of its rapidly increasing and predominantly young population, in the face of severe poverty and cycles of natural disasters. Following the change of government in 1991, the new government of Ethiopia developed a national health policy, which was followed by the formulation of four consecutive phases of comprehensive Health Sector Development Plans (HSDPs), starting from 1996/97. Encouraging private and NGO participation in the health sector is among the core elements of the policy.

As part of the nation's overall health plans and strategies, Ethiopia has promoted partnership across sectors as a way to tackle the health service problems. In fact, the Ethiopian health care system has been augmented by the rapid expansion of the private-for-profit and NGOs sector playing a significant role in boosting health service coverage and utilization, thus enhancing the public/private/NGOs partnership in the delivery of health care services in the country (FMOH, 2010). The partnership arrangements across Ethiopia mobilize the collective effort of state and non-state actors in the design and delivery of health services. This paper therefore investigates these partnerships to better understand their formation and function as new form of governance in Ethiopia.

\section{Methodology}

\section{Case study: AMREF-RMNCH}

We use a single case study research design to explore the interaction between state and non-state actors in health service delivery. The study focuses on a collaborative project implementing maternal and child health programs in the Amhara region, in the North Shewa zone of Ethiopia. Amref Health Africa (also known as African Medical and Research Foundation) is an international health development organization that works with diverse actors including local NGOs, and government agencies - to create and strengthen local programs for ensuring access to 
health services. In 2014, Amref took the initiative to bring a specific program named Reproductive, Maternal, Neonatal, and Child Health Care (RMNCH) to the region studied. Amref takes an integrated approach toward maternal and child health care, combining this with sexual and reproductive health. Activities include strengthening the functional level of health facilities, building the capacity of the health system especially at district level, building the capacity of health workers, and mobilizing community demand and ownership over maternal and child health care interventions. Most of these activities take place at district level and sub-district level where health centers are located.

In addition to Amref, the project involves both state and non-state actors. Representing the state at zonal level, the Zone Office of Economic and Development (ZoFED), the Zonal Health Department, and the Women and Children Affairs Department signed an agreement with Amref and assume the role of supervising the project. At district (Woreda) level, the district administration, the District Health Office, the District Economic and Development Office, and the Women and Children Office are involved. Amref also created an alliance with three local NGOs: Talent Youth Association (TYA), Youth Network for Sustainable Development (YNSD), and Family Guidance Association (FGA). At district level all actors are pulled together and work together on practical matters. The project activities also extend to the sub-district (Kebele) level where the health centers and health posts are located. All health offices at different levels from region to zone to district are state partners. Yet, the district office has a strong role as it is placed at the core of the partnership and mobilizes the available health institutions and actors within the state structure.

\section{Data collection and analysis}

Data was collected through in-depth semi-structured interviews, Focus Group Discussions (FGDs), and document analysis. Data collection took place at the federal and local (district and sub-district) level. At the federal level, interviewees were identified from federal institutes considering their expertise and affiliation to the subject of study. Especially, experts from the Federal Ministry of Health (FMOH) provided their perspective on the interaction between state and non-state actors for health service delivery. At the local level, individuals were interviewed from both state and non-state actors' sides actively engaged in the project. Participants were identified through a preliminary discussion with the project manager and district officials. Interviewees included one representative from each NGO represented in the project, and one department head and one expert from each of the local state agencies participating in the project. A total of 17 persons were interviewed.

Additionally, two FGDs were held at the local level. The first FGD involved seven participants, mainly local officials at district level and non-state actor representatives. The second FGD was held in a health center at subdistrict level and included ten participants from state actors, community members, health professionals, health extension workers, and community volunteers. Interviews and focus group discussions were conducted face-toface in the Amharic language. The conversations were recorded and transcribed while translating to English. Throughout the data analysis, in addition to these transcripts, field notes and documents such as policy documents, proclamations, strategic plans, and project guideline documents were reviewed repeatedly to get the full picture and understand the contextual setting of the research. When necessary, audio recordings were used to ensure accuracy. Qualitative data analysis, using Nvivol1 software, was used to identify and describe the prevailing practices. The qualitative method suited this study as it emphasizes describing the collaborative process. A coding scheme was used to organize textual data gathered from interviews, FGDS and documents into different theoretical elements that provide the focus for this study as a theoretic framework.

\section{Case Study of the MSP at Tarmaber Woreda in Ethiopia}

Ethiopia, as many developing countries, is struggling to ensure access to basic health services for large proportion of its rural poor citizens. These efforts are shared by the different government tiers in the structure of the government from federal to regional to local. Despite some improvements in the health sector, various problems 
Hiwot

reside in the society that need a joint effort. For instance, according to the UNDP Human Development Report, Ethiopia is a country where 353 women die from pregnancy-related causes for every 100,000 live births (UNDP, 2015). Therefore, health in general in Ethiopia and maternal and child health in particular requires the contribution of various actors. Following this, health service delivery in Ethiopia takes place through an array of state and non-state networks. Network as a complex phenomenon involves interdependent interactions between multilayered networks of actors from different parts of society; they collaborate to promote a commonly agreed purpose through negotiation and in relatively institutionalized framework while maintaining their organizational autonomy (Sørensen and Torfing, 2006).

\section{The overall functioning of the MSP at Tarmaber woreda}

Amref Health Africa is an international health development organization based in Africa that works with diverse actors - including local NGOs, and government agencies - to create and strengthen local programs for ensuring access to health services. Amref took the initiative to bring a specific program named Reproductive, Maternal, Neonatal and Child Health Care (RMNCH) to the region studied. This Amref MNCH project aims to improve sexual and reproductive, maternal, neonatal and child health status of the people in the project's area. Starting from 2014, the program became the main focal area in the North Shewa Zone. Amref takes an integrated approach toward maternal and child health care, combining this with Sexual and Reproductive Health (SRH). As a result, joint activities incorporating different partners are directed toward this initiative. These activities include strengthening the functional level of health facilities, building the capacity of the health system, especially at district level, building the capacity of health workers, and mobilizing community demand and ownership over maternal and child health care interventions. Most of these activities take place at district level and sub-district level where health centers are located.

In addition to Amref, the project involves both state and non-state actors. Especially, regional government institutions at zonal and district level are involved, assuming different roles. At zonal level, the Zone Office of Economic and Development (ZOFED), the Zonal Health Department, and the Women and Children Affairs Department signed an agreement with Amref representing the state and later on they assumed the role of supervising the project. At district level, the district administration, the District Health Office, the District Economic and Development Office, and the Women and Children Office are involved in the project. Amref as initiator and major NGO in the project also created an alliance with three local NGOs that joined in implementing the project, namely Talent Youth Association (TYA), Youth Network for Sustainable Development (YNSD) and Family Guidance Association (FGA).

It is on the district level that all actors are pulled together and work together in practical matters. The project activities are also extended to the sub-district (Kebele) level where the health centers and health posts are located. The major state partners are all health offices at different levels from region to zone to district. Yet, the district office has a strong role in the partnership at it is placed at the core of the partnership and mobilizes the available health institutions and actors within the state structure. Amref doesn't want to create the partnership only with organized institutions, but it wants to engage with others too. Working with state agents such as Health Extension Workers (HEW) and community volunteers (e.g., the Health Development Army (HDA)) was key to this. In the past few years the Ethiopian government invested in designing and installing a health service delivery structure with resilient focus on Health Extension Programmes (HEP). The program has been implemented through the active and dedicated role of actors, including the HEWs and HDA. Both HEW and HDA are involved in the project activities. Generally, the partnership engages both state and non-state actors tied by formal agreement and in every possible way.

Having described the partners involved in the MSP under study, we next describe the overall functioning of this MSP by referring to interdependency between actors, interaction, institutional structure, self-regulation, and the extent to which the MSP results in the production of public purpose. 


\section{Interdependency of actors in the MSP}

A number of interdependent actors participate in Amref-RMNCH project. With differing missions and resources, the project helps organizations to come together and work on various health issues that are prevalent in the Tarmaber district. The instigation of the project in network form implies the mutual dependencies of the organizations because of the division of resources and the interdependency of goals.

According to our respondents, there is an explicit interdependency among actors working in the project that is mainly attributed to the fact that all actors included in the partnership bring resources and specific competencies that can be of a certain value to other actors. For example, Family Guidance Association (FGA), is more experienced in reproductive health service provisions with extensive health facilities and model clinics, which can be more valuable in connection with reproductive health activities. TAYA, a local NGO, has good experience in youth-related work, so it focuses on youth focus intervention services. Amref, as a lead NGO, primarily focuses on resource mobilization, negotiating with donors, and bringing international experience. Actors in the partnership bring important resources that range from material to human to financial to the collaboration. It was evident during the project activities that the state actors possess important resources and expertise that the project requires, such as infrastructures, human resources (professionals), and even some resources that are difficult for the non-state actors to obtain, like information, and the authority to license. In addition to some unique competencies and expert knowledge, non-state actors bring various resources to the collaboration, including materials, supplies, money, time and information.

Interviewees recognize that there is a need to find a way to pool fragmented resources and competencies from various sources. This is especially emphasized from state respondents where they point out that there are resource constraints that require joint actions. For instance, respondent SR9 points out that from the government side, the annual budget allocated for health is not sufficient to execute activities: "Fifteen percent of the district budget is supposed to be allocated for health, but we can't even get 10 percent, so we still need support from partners."

In fact, while their statements support the overt reality of the country, they specifically show the gaps in their district. Specifically, in the health centers there are shortages of medical supplies, medical equipment, inadequate infrastructure, and most importantly there are clear limitations on professional knowledge, skills and capacity needed to address varied reproductive, maternal, and child health issues in the district. With its overstretched capacity, the state lacks resources and necessary competencies to provide services and bring the desired change in health within a short period of time.

The other actors also confirm that they require certain competencies from other actors. The international NGO respondent (NSR2) explained that its organization seeks the local knowledge and specific expertise of the other local NGOs, the facilitating role of the state, and the collaborative effort of the agents and community groups. Other non-state respondents (NSR3, NSR4) responded that their organization wants international experiences from the international NGO. In this sense, the Amref-RMNCH collaborative interactions are purposive to the extent that actors with varying resources and competencies work together to deliver the health services.

In the Amref-RMNCH project, actors had a chance to bound their interaction through reciprocal actions to realize their respective missions as perceived. In governance networks, actors' mutual interdependency is expected as there is a division of resources and interdependency of goals (Lee, 2003). Respondents explicitly recognized the reciprocal actions involved in the process. Some of the local NGOs are asked to join the AmrefRMNCH project because their mission areas are tangibly related to reproductive and maternal health, and because there is an identified need for a particular expertise. In general, district officials welcomed the Amref-initiated project as it aligned with their objectives. The majority of interviewees indicated that they perceive their own organizational goals to be furthered by establishing partnerships with other organizations on health issues. However, collaboration occurs between partners implementing the activities related to maternal and child health because it is impossible for each partner to function in an environment filled with complex problems without partnering with others. A State respondent (SR) specified that: 


\section{There are a lot of problems in our district that require a lot of expertise and resources because of the fact that neither the state organ nor non-state organ has sufficient capabilities and expertise to address the complex and broad range of problems in health.}

Throughout the partnership process, strong cooperation is required between both non-state actors and state actors at different levels; from district administration to local health centers' professionals to implement the partnership activities. The project activities would not be realized if the state actors do not facilitate the ground for non-state actors' participation; and in turn, without the program, the state could not effectively help mothers to deliver children at health center level, both due to the lack of basic health delivery instruments and supplies (provided for free by Amref) and its lack of trained professionals (provided by a FGA in collaboration with AMREF). Hence, there is visible interdependency in Amref-RMNCH project among actors working together for health service delivery. We had also the chance to observe the resources mobilized in the Tarmaber District. In the Armenia Health Center, which is one of the sub-district health centers, there were various materials supplied by Amref. Among others, oxygen and vacuum units were very essential in assisted delivery of pregnant women. Immaterial resources are also transferred in the form of training for the health professionals. Midwifes in the health center receive training that equips them to perform some health procedures for the society. This suggest that the participants are pooled together based on the specializations needed to carry out the project's wide array of activities. MSPs as a form of network can be important vehicles for resource pooling, mutual exploration, and knowledge creation (Agranoff, 2006). Most importantly, they can open up new possibilities that would be hard for one, two, or even three organizations working together to achieve.

An additional form of interdependency can be created when networks are able to pool actors who can demonstrate that they have a stake in the issue at hand. Interdependency is confirmed in the stakeholders' acknowledged, shared mission and objectives concerning health and health-related issues and their determination to decrease maternal and child health. Health is one of the most important focus areas in Ethiopia and the state demonstrated this by taking the responsibility to lead the activities of health at all levels. The nonstate actors involved in the partnership demonstrate that they have a mission to shoulder the problems of the society through their commitment and long-standing effort in the community. This element of interdependency is also well reflected in our case related to HDA and HEW. Respondents from both groups clearly stipulated that they have a stake in health issues. Respondent (SR4) puts it as follows:

\section{At least for alleviating mothers' and children's deaths everyone and every segment of the society has the responsibility. I can say everyone shares the same value and the responsibilities are shared at each level of the society whether you say it at Kebele (sub-woreda) level, or community group arrangement level.}

As we observed, HDA as community group serves the community without any incentives as they understand they have a stake in the issue and want to contribute something of value to the collaboration effort.

\section{Interaction through negotiation}

\section{Negotiating at the start of the MSP}

International and national non-state actors can only form a partnership with state institutions by navigating the federal agencies or regional legal and administrative processes. They are first required to be legally registered and certified and also to enter into a general agreement with a relevant agency to which they have to periodically report. They are required to prepare a proposal; there is a proposal evaluation team at both the federal and regional levels which is responsible for evaluating the proposals before non-state actors sign any agreement. A team of experts evaluates the proposal and identifies gaps that are open for negotiation with non-state actors. As the respondent from the FMOH (SR1) and a member of the proposal evaluation team explained, the government puts its own criteria to evaluate the proposals that come from non-state actors, and they only accept those proposals that match strategies, priority areas, and interest put forward by the government. Finally, the team will 
call back the non-state actors and negotiate on areas that they can amend and work on together. According to the state representatives at federal level (SR2), the proposal evaluation system set by the state provides an opportunity for negotiation in the sense that state representatives at federal and regional levels focused on continued communication and discussion with non-state actors instead of merely taking a decision. However, a respondent from non-state actors (NSR1) explained that at the federal and regional levels these negotiations are subject to subjugation. First, all civil society organizations are expected to work on the state's agenda and prepare proposals based on state programs and strategies. Thus, the negotiation circulates around the details of the program not on the overall program areas. Second, sometimes the negotiation takes place within a framework that hinders common understanding and joint action. This usually happens as public authorities focus on strict formalities and administrative issues rather than the real significance and benefits of the joint action. For instance, at the start of the Amref-RMNCH project, there were briefings on project activities and negotiation at the regional health office. The regional office demanded Amref to take out the names and responsibilities of other local NGOs from the proposal as they want to make an agreement with Amref independently. Although the regional office is well aware of the fact that at the local level the operation takes place with the involvement of all actors, it only wants to make an agreement with Amref as it wants to make Amref solely responsible over resource distribution. With no common consensus, Amref agreed and took the alliances and made an agreement with the regional health office.

However, we were able to observe government negotiating with non-state actors on its own terms and conditions while non-state actors also come up with the gaps that are already pre-identified by the government. Hence, often times the negotiation outcomes are in favor of both sides. Even if they are not happy, decisions will often be made on the basis of a "rough consensus" where grievances are unavoidable, but tolerable.

In general, formal agreement was used within this partnership to establish a clear division of roles and responsibilities among the signing actors. As described in the introduction, Amref as a lead agency signs an agreement with regional government and is designated with roles and responsibilities specified in an MOU. However, much discretion is left to the local state agencies and non-state actors to determine an action plan to transform the proposal into activities. Though state actors here seem to be the ones to designate the ground for play, but their dependency on the other actors induces them to negotiate with other actors to attain the resources needed to achieve health related goals. The non-state actors are also willing to negotiate as they are dependent on the others for accomplishing their goal.

\section{Negotiating during the implementation of the project}

Negotiations also occur when non-state actors go down to the local level and work with state actors at a practical level. The negotiation here is actually different from what happens at the federal or regional level. Actors here negotiate on the magnitude, nature, time, and modalities of activities' implementation in the community. Hence, unlike the negotiation at the federal level, which can be characterized as a "take it or leave it" negotiation, at the local level negotiations end up in relative consensus. This is basically because government actors at the local level accept that, on the one hand, non-state actors already passed the criteria at the federal or regional level and, on the other hand, as state actors they need the non-state actors' support. For example, both state and non-state actors (SR7 and NSR2) explained how they executed a given activity through negotiation within the project. The goal of the activity was to provide customer friendly services at different health centers. Amref, FGA, and Woreda health office, which was representing the state, sit together and negotiate on different issues, like which and how many health centers to include, or which activities to finish first. Each actor has its own expertise and responsibilities to execute. Amref was assigned to furnish the centers, renovate the service provision areas, and supply materials and equipment. FGA's task was to train the health professionals in the health centers, and the state actor was expected to facilitate and coordinate the whole implementation process. In the end, they managed their negotiation and executed the activities in sequence and on time. Unlike the negotiation at the regional level, this takes place in a wider framework of deliberation that facilitates understanding and many respondents confirmed that the negotiation helps them to identify their roles, responsibilities, and obligation. 
In comparison with regular - often authoritative and command-driven - interaction that occurs in state institutions, interaction procedures in the Amref project were, according to respondents, characterized by discussion. All respondents acknowledge that, whenever they face some issue that requires negotiation in their joint activities, they engaged in discussion, reached an agreement, and afterward executed the decision with the sense that they are fulfilling their responsibility. Though most respondents acknowledged there is a room for negotiation and reaching an agreement, some of the respondents from non-state actors take an extra caution in their negotiation with state actors as they don't want to damage their smooth relation afterward. A respondent from NGO (NRS2) stressed:

\section{When we face something that requires negotiation with others, we are very systematic, and we usually come with some ideas in our mind which could possibly satisfy the interest of state actors while maintaining our interest. Otherwise, we wouldn't agree on the issue and later on, our relationship would be spoiled.}

Hence their caution in negotiation and thereby compliance with the decision does not come from fear of legal sanction. Rather they comply with the decision in order to avoid unnecessary problems with state actors. In doing so, non-state actors internalize the government system and regulations which indirectly helps them to play within the rules of the game.

\section{Institutional setting}

The interaction of actors in MSP takes place in specific institutional setting that involves social interaction and formal rues. Both formal and informal agreements provide the institutional setting for the MSP while specifying the roles and responsibilities of the actors.

\section{Regulatory framework: Memorandum of Understanding and an action plan}

The interaction and negotiations of actors in the Amref project take place within an institutionalized framework. The institutional setting for actors involved in an MSP can be established when state and non-state actors enter into a formal agreement. In the case study, Amref as lead NGO signed a Memorandum of Understanding (MOU) with the federal, regional, and zonal state authorities. The MOU provides the framework for the working relationship between the parties by specifying actors' "duties and responsibilities." Hence, for the partnership the first layer of the framework comes from the agreement with the federal and regional governments. After signing the MOU, the project proposal and accompanying documents are sent to the district level. Even if the district government has the jurisdiction to accept or reject an intervention, it cannot authorize non-state actors' intervention without higher authority's approval. All interviewees mentioned that the MOU is used to formalize relationships between participants and later it is used by state agencies as a basis to monitor the activities. All stakeholders in the MSP indicate that there are formal meeting opportunities involving all actors. They meet and conduct the mid-term and terminal evaluations regularly; sometimes they even go to the project sites. There is also a GO-NGO forum at the district level organized by state institutions. This forum serves as an evaluation stage for the project. However, it seems that stakeholders give more attention to communication and discussions that are held in the MSP when the need arises.

The second binding agreement between actors comes at the district level when actors sit and develop an action plan based on the proposal presented at a higher level. A document containing the action plan and program details is sent to each stakeholder involved in the project and later on it is used to evaluate the activities. The program document stipulates each actor's activities, role, and responsibility, and the timetable for executing the activities. The MSP is functioning in a stipulated regulatory framework that provides roles and procedures for overall interaction of actors in the MSP.

The partnership involves regulatory aspects of the institutional framework through the utilization of an MOU and action plans. This in turn leads to the emergence of rules that regulate the behavior of actors and facilitate 
interaction within the partnerships. Such rules are relevant as they facilitate interaction in networks, thus reducing transaction costs and influencing the performance of networks (Koppenjan \& Klijn, 2004; Ostrom, 1986).

\section{Administrative structure of the MSP}

When actors agree to work together in an MSP, they enter a network-based form of cooperation that significantly differs from the usual top-down working style of local government. In executing their activities, actors may follow different forms of structure, which give an institutional frame for their activity. According to Bryson et al. (2006), actors in a network type of relation realize their activities in varying forms: (a) self-government in regular meetings; (b) a formal coordinating organization in the network; or (c) an administrative organization, which is supporting the network in technical matters.

In our case, we can see the administrative structure of the network at two levels. First, the organized non-state actors created two project groups/committees, namely a technical committee and a steering committee. The project's steering committee is designed to include all partner organizations' representatives and meets four times a year. As respondents explained, the committee does not meet per schedule. The committee discusses administrative issues, donor questions, and solves pressing problems. The technical team is designed to include organizations' representatives that are close to the technical works of the project and meets every month to review technical issues at the implementation level. Generally, it is a platform for the actors to trace the project progress, exchange information, and plan activities together.

Second, MSPs as a network involve the deployment of a coordinating organization to regulate activities. The position of the BoFED in the MSP merits attention. When the office signs an agreement with the non-state actors as partner, it is guaranteeing its formal coordinating role in the partnership. The current administrative structure of the country provides the finance, economic, and development offices at different level of the state structure with the responsibility to coordinate and control the budget utilization of collaboration activities. The assignment of such coordinating organization in MSPs shows that extensive controlling and coordinating responsibilities are completely monopolized by the state.

Among other, the institutional setting of the Amref-MNCH project involves funding. All respondents from nonstate organizations mention the use of grant contracts to formalize relationships between participants. Amref as a lead organization brings the funds from international donors and it is the only source of financial resources within the MSP. Amref acts as a donor in its relation with the other non-state actors and their relation is characterized as grantee and sub-grantee. They have a common document that guides their relation called the sub-partners/grantees management guideline. The document outlines guiding principles on how to work, at what level they should engage and how to utilize funds. A respondent (NSR2) from Amref stated:

\section{The allocation of funds through sub-grantee to local NGOs are used to support activities that directly complement the project, and basically roles to sustain relationships are determined by stipulations within the grant contract document.}

On the other hand, state actors assume the role of controlling budget utilization of the project. When an agreement is signed at the start of the project, Amref preset the activities and budget planning and BoFED as coordinating state actor takes the responsibility to monitor the utilization of the budget according to the activities.

\section{Communication as informal agreement}

In addition to the formal agreements, informal agreements are also used in forming the institutional setting for the MSP. In service delivery projects that involve various stakeholders, there is always a need for communication and many communication patterns can emerge between actors in the project. We found that actors built a strong bond and that they tend to rely on phone, email communication or interpersonal meetings. A respondent from the district office indicated (SR2): 


\section{Our works are interdependent; we read and communicate each other to execute the activities in sequence and on time. We make desk review, we sit together and discuss, plus we use email, we have also frequent day to day communication on phone.}

Other interviewees suggested that there is a strong bond in the project that brings them to consider one another as friends. Beyond contract stipulations, actors are able to execute their responsibilities through dialogue, and good relationships. Such communications patterns are significant because non-state actors are able to avoid the regular - often bureaucratic - communication procedures followed by the Ethiopian state institutions.

\section{The level of self-regulation within the MSP}

The state structure is devolved as involving different levels of government that are related in a chain of command, but partnerships are formed aiming to work differently from the state structure. As described in the case study, the formal agreement of actors in the partnership is specified in the MOU with no party identified as lead organization in the partnership. Rather both parties are identified with related obligations for project implementation. However, much discretion is left up to the non-state actors and local state actors where the project is implemented to determine details of activities and engage in the complex negotiation involved to move forward. This in turn gives a chance for interdependent actors in the Amref-RMNCH project to bring their ideas, resources, and innovation to production of services. For example, quality improvement initiatives were implemented in one of the health centers as part of the whole project. Though the initiative was applied as a pilot program, it was found successful and there is an effort to scale it up to various health centers.

According to the participants in the MSP, a program document is prepared at the start of the project that illustrates each actors' ideas, resources, and capabilities, and is used in directing their activities afterwards. The program documents serve as an action plan that portrays the activities to be performed, the time period for executing these, and the responsible partner for the activities. Actors in the MSP are executing their agreed-upon activities within the institutional framework they established through regular interaction. This helps them to use their own ideas, resources, and capabilities to regulate the production of services in the project rather than receiving orders through the chain of command. Thus, there is less chance for the MSP to become part of the formal chain of command and lose its self-regulation completely. This shows that the MSP is able to retain some form of closedness, which, according to van Bortel (2009, pp. 171) "enables organizations to retain their focus and incorporate only a limited amount of the complexity and environmental turbulence into their activities. Closedness is often the result of the power and autonomy of the actor(s) involved." From the perspective of executing activities, the partnership is self-regulating; it is working in accordance with the agreed plan. The establishment of this formal arrangement for executing activities creates opportunities for participants to identify ways to provide health services using a holistic approach. Interviewees recognize the collaborative arrangement as a way to execute the activities in Tarmaber district through a network approach. Discussion during focus groups discussion revealed that each partner addresses the piece of activities assigned, and each piece of activities impacts the larger health system. It was evident during the interviews that participants feel personally connected to the work they do and care about the project.

However, the MSP is not able to retain its self-regulation completely as it involves a complex interaction between state and non-state institutions in a certain environment. First, the operating environment at different levels is filled with state actors that regulate the partnership. For instance, RHB and Zonal health department supervise the progress of the project and regulate actors' activities. They control and follow up the implementation of activities at local level by means of reports, evaluation protocols, and sometimes field visits. Therefore, state actors are acting as a partner and as a regulatory body in the network, which affects the self-regulating capacity of the network.

Even at the local level, where a close collaboration and daily interaction exists, state actors have a tendency to put pressure on the partnership; as one of the respondent from the district administration (SR9) said: 
At district level, we follow those non-state actors that come to work in our district and we control them and take action if necessary. For example, if they are building a health center, they put the fund on our finance account, and then they are expected to justify their expenditure, and the district engineers follow the construction, we also give feedback. If we find the construction under standard, we abolish it.

This finding aligns with the idea put forward by Agranoff (2006) that networks can sometimes deliberate new strategies and programs, but in many networks, government administrators at all levels present themselves as core actors and they use their position to inject legislative, regulatory, and financial considerations into the network mix.

Second, MSP participants indicated that the state exerted effort to put into place a regulatory structure at different level of the state structure that sets strong accountability measures for collective actions. As one of the state actors describes it (SR1):

\section{In order to check whether the activities are going in accordance with the rules and agreement, government has set a controlling department in every level of the government structure. So the department controls whether the project is going on as agreed on, benefiting society as it was designed, and if there is a problem, efforts will be made to correct it in the middle. Finally, with all stakeholders' presence, the activities will be evaluated.}

More specifically, the partnership is accountable to BoFED and the district administrative council. Both state institutions monitor the performance of the partnership. Thus, the self-regulation of the MSP is limited by the accountability measures set by the state. One of the important concepts in self-regulation is how accountability measures can erode autonomy (Hodgson, 2004). Given the accountability measures set by the state, state and nonstate actors in the MSP are not autonomous from the state. This finding typically coincides with Johnston's (2015) finding that the state, although a participant in networks, plays a dominant role in governance networks.

\section{Production of public purpose}

In any type of collaborative arrangement, the engagement of actors towards production of public purpose requires a common understanding about the issue that pools them together and the shared purpose among the actors. Shared understanding of the issue is a vital value that all stakeholders in the MSP have to create (Poocharoen \& Ting, 2015) as it helps to avoid "miscommunication and misdirection of efforts" (Ansell \& Gash, 2007). All participants in the MSP hold a common understanding, which is about creating a healthy society, more specifically, to decrease maternal and child mortality rates. This is especially significant given the fact that Ethiopia is a developing country dealing with many health problems. Mobilization of resources and networks towards this cause is of national interest. To that end the joint contribution of state and non-state actors in the sector in general, and in maternal health in particular, is exemplary. One of the factors that can create harmony is a common understanding about the issue at hand, and all respondents show the same idea of the nobleness of the cause for which they are working.

It was evident during our discussion that all actors perceive that the partnership is contributing to the production of health services that can help in alleviating the health problems. However, few evidence was presented that could attach the partnership with the production of polices and values that can extend beyond the immediate needs of the society. Though all respondents try to assure that the partnership is a good forum that has been helpful in bringing solutions to the current pressing problems, it seems that they have less agreement on specific objectives they aim to achieve in practice beyond tackling the maternal and child health problems. This mainly concerns the state actors as most of them perceive that the current collaboration is meant to fill the current gaps and solve problems. This is well described by one of the expert from district health office (SR7):

Focusing on current problems and filling the gaps often marginalize other issues, most importantly it prevents us from realizing the full potential of the NGOs. 
On the other hand, non-state actors are content with how the project is helping them in developing their capacity.

There are some examples that the interaction of state and non-state actors in collaboration settings could help to produce public purpose beyond the stated goals and this is especially found relevant for state institutions in the Amref-RMNCH project. For example, societal actors may demonstrate new ways of conducting activities at local level which are difficult for state agencies (Clark, 1995). This in turn helps them to document their experience and share this with state actors that could be used as input in policy formulation. One way to share experience at the local level is through a government-NGO (GONGO) forum. Such a forum is organized by BoFED and gives an opportunity to both non-state and state actors to meet and share experiences. The non-state actors found this forum important to create awareness in the government of the effects of the health policy on the different sections of population. An important aspect of the horizontal relation of multiple actors in networks was the enhanced need for negotiation and discussion. This involves bringing new ideas and applying different mechanisms. Respondents indicated that the Amref-RMNCH project allowed the incorporation of ideas and new initiatives. This is significant because it helps creation of understanding and values. Thus, the practices in the partnership could be a good opportunity to input ideas to local state institutions to acquire flexibility as compared to the traditional strict command rule.

Despite the existence of this shared purpose, some respondents raised the short life of the partnerships as a problem that affects their efforts toward production of public purpose. The fact that the partnerships are mostly project-based poses a question of reliability and sustainability of engagement towards continued progress in the sector. Moreover, state actors in the area also believe that networks and partnerships are not governance systems upheld at a policy level to exist across time. State respondents argue that non-state actors' role will no longer be needed when the government is capable of delivering all health services by itself.

\section{Key Findings and Conclusion}

This case study of the MSP in the Ethiopian health sector has brought some key findings. In this concluding section we first summarize the discussion on the functioning of the MSP that was investigated in the case study, followed by a brief reflection on the theoretical and practical implications.

\section{Explaining MSPs from a network governance perspective}

In developing countries where resources are scarce, in order to produce and distribute public services the presence of networks is bound to become more prevalent. There is much to explore in terms of how they are organized and operate in actual practice. The paper explained how horizontal partnerships for public service delivery are organized and operate in Ethiopia. To this end, we proposed a theoretical framework derived from network governance theory and studies a case. We derived a list of theoretical propositions from the theory and confronted them with the empirical evidence collected in the course of the research.

In explaining the organization and operation of the MSP, we found that network governance theory presents important insights. First, the interdependency of the various societal actors plays a significant role in establishing the MSP in the case of the studied district. We have seen that interdependency embedded by the collection of actors with different competencies and resources helps the district to provide health services that otherwise will be difficult to do. Recognizing the interdependency, the MSP also stretches into incorporating the community groups that have resources and stakes in the issue. We, therefore, suggest that interdependency of various societal actors plays an important role in establishment of horizontal partnerships.

Second, we considered a related proposition of the network-governance theory: interaction through negotiation. Negotiation lies at the heart of an actor's relationship in the network form of coordination as it gives a chance for the actors to interact through discussion and deliberation. Therefore, this proposition entails that actors in horizontal governance interact through negotiation. In this case, we found that actors' interaction at the 
local level is more framed by negotiation as compared to at the regional and federal levels. Certainly, the day-today relation of actors bound by the interdependency frames their interaction through negotiation that furthers common understanding and action. This in turn enhances the functioning of the MSP in contributing to health service delivery. We have also seen how the negotiation of actors at the federal and regional levels was constrained by strict administrative formalities and pre-ordained frameworks despite the recognized need for common effort towards alleviating maternal and child health problems. This is not to say that the negotiations at the local level are perfect, which is not the case, but the day-to-day interaction of the actors at the local level pave the way for smooth negotiations. In the case of institutional frameworks, we have emphasized that formal agreements and action plans frame the interaction of the actors in the MSP through establishing roles and procedures. Informal agreement through dialogue and strong bonds was found, as important as the formal agreement in forming the institutional framework, thus positively affecting the operation of the MSP. Such an informal agreement helps to establish values like trust and commitment, which further provide a normative framework for the interaction of actors in the MSP. Despite the chance that the institutional framework can involve more elements, it was dominated by regulatory arrangements that spread rules, roles, and procedural elements.

We argue that a network governance stipulation about self-regulation of networks helps explain the organization and function of the MSP in the case study district. First, a well stipulated work plan embedded in the overall institutional framework helps the MSP to maintain its self-regulation and develop closedness that helps to use its own ideas, resources, and capabilities to regulate the production of services. The key point is that the limits on self-regulation of the MSP can influence the organization and functioning of the MSP. We also found evidence that supports the argument. The operating environment at different levels is filled with state actors that regulate the partnership.

State actors are acting as a partner and as a regulatory body in the network, which affects the self-regulating capacity of the network. Although partnership does involve a network of state and non-state actors, there are asymmetries of power.

Production of public purpose in the MSP to some extent helps to explain the organization and function of the MSP. We have seen that the collaboration effort can help the societal actors to develop new methods and techniques that can be scaled up to various areas and be an input in policy formulation. However, meeting shortterm objectives and supporting immediate needs seems more prominent in the case study as compared to production of public purpose.

\section{Conclusion}

Network governance involving public and non-public actors can in fact depict the new, changing societal governance order emerging within the transformation from government to governance. This study sought to understand the features of new governing structures through analyzing the actual operation and outcomes of collaborative networks. By analyzing a specific case study at the local level, the study sought to meet several goals.

The first goal is to emphasize the importance of evaluating network governance in developing the country context. The finding in the study proves that concepts and theories must be tested through comparative analysis as it increases the theoretical and practical relevance of the concepts.

Second, the paper discusses the case study of an MSP organized for health service delivery in Ethiopia and frames the analysis of the case within the network governance framework. By doing so, we test our basic argument that network governance can help us to understand the shift from government to governance. We observed that MSPs are used as one of the governance tools to deal with complex health problems at the local level. This is done through the utilization of the resources and capabilities of various societal actors. Although it is difficult at this point to generalize that there is a complete transformation to governance, the findings indicate that MSPs are emerging as an optional governance tool in the process of governing. 
Third, the analysis of MSPs as network governance also helps us to question the dominant discourse that portrays network governance as an effective governance tool to deal with complex societal problems. We have observed that MSPs have the potential for the society to enhance interdependent interaction and deliberative practices and thereby improve health service delivery.

\section{References}

Agranoff, A. (2006). Inside collaborative networks: Ten lessons for public managers. Public Administration Review, 66(s1), 56-65. https://doi.org/10.1111/j.1540-6210.2006.00666.X

Banerjee, A., Murphy, E., \& Walsh, P. P. (2020). Perceptions of multi-stakeholder partnerships for the sustainable development goals: A case study of Irish non-state actors. Sustainability, 12(21), 8872. https://doi.org/ 10.3390/su12218872

Bäckstrand, K. (2006). Multi-stakeholder partnerships for sustainable development: Rethinking legitimacy, accountability and effectiveness. European Environment, 16, 290-306. https://doi.org/10.1002/eet.425

Cammett, M. C., \& MacLean, L.M. (Eds.) (2014). The Politics of non-state social welfare. Cornell University Press.

Christensen, Tom (2012). Post-NPM and changing public governance. Meiji Journal of Political Science and Economics1, 1-11.

El-Saharty, S., Kebede, S., Olango Dubusho, P., \& Banafsheh, S. (2009). Ethiopia; Improving Health Service Delivery. Health, Nutrition and Population (HNP) discussion paper. World Bank.

https://openknowledge.worldbank.org/handle/10986/13695

Federal Democratic Republic of Ethiopia, Ministry of Health (2010). Health Sector Development Programme IV, 2010/11-2014/15.

Fimreite, A. L. and Lægreid, P. (2009). Reorganizing the welfare state: Partnership, networks and accountability. Public Management Review, 11(3), 284-297. https://doi.org/10.1080/14719030902798198

Fulda, A., Li, Y., \& Song, Q. (2012). New strategies of civil society in China: A case study of the network governance approach. Journal of Contemporary China, 21(76), 675-693. https://doi.org/10.1080/10670564.2012.666837

Gregory, R. (2003). All the king's horses and all the king's men: Putting New Zealand's public sector back together again. International Public Management Review, 4(2), 41-58.

Head, B. W. (2008) Assessing network-based collaborations. Public Management Review, 10(6), $733-749$. https://doi.org/10.1080/14719030802423087

Hemmati, M. (2002). Multi-stakeholder processes for governance and sustainability. Beyond deadlock and conflict. Earthscan. https://doi.org/10.4324/9781849772037

Hodgson, L. (2004). Manufactured civil society: Counting the cost. Critical Social Policy, 24, 139-164. https://doi.org/10.1177/0261018304041948

Johnston, K. (2015). Public governance: The government of non-state actors in 'partnerships'.Public Money $\mathcal{E}$ Management, 35(1), 15-22. https://doi.org/10.1080/09540962.2015.986860

Kjaer, A.M. (2004). Governance. Polity Press.

Klijn, E. H., \& Koppenjan, J. (2016). Governance networks in the public sector. Routledge. https://doi.org/10.4324/9781315887098

Larsson, O. L. (2019). The governmentality of network governance: Collaboration as a new facet of the liberal art of governing. Constellations, 27(1), 1-16. https://doi.org/10.1111/1467-8675.12447

Lee, M. (2003). Conceptualizing the new governance: A new institution of social coordination. Institutional Analysis and Development Mini-Conference, 1-26.

http://www.indiana.edu/ workshop/seminars/papers/y673_spring_2003_lee.pdf

Maes, J., Parra, C., Mertens, K., Bwambale, B., Jacobs, L., Poesen, J. Dewitted, O., Vrankenb, L., de Hontheime, A., Kabasekec, C., Kervyn, M. (2018). Questioning network governance for disaster risk management: Lessons 
learnt from landslide risk management in Uganda. Environmental Science and Policy, 85, 163-171. https://doi.org/10.1016/i.envsci.2018.04.002

Moloney, K. (2013). Governing without collaboration: State and civil society relations in Jamaica. International Public Management Review, 14(1), 1-26.

Meulemann, L. (2008). Public management and the metagovernance of hierarchies, networks and markets: The feasibility of designing and managing governance style communications. Physica-Verlag. http://dx.doi.org/10.1007/978-3-79082054-6

Pattberg, P., \& Widerberg, O. (2014). Transnational multi-stakeholder partnerships for sustainable development; Building blocks for success. Ambio, 45, 42-51. https://doi.org/10.1007/s13280-015-0684-2

Peters, G. (2010). Public administration in the United States: Anglo-American, just American, or which American? In M. Painter \& G. Peters (Eds.), Tradition and public administration (pp.114-118). Palgrave/Macmillan. https://doi.org/10.1057/9780230289635_9

Pierre, J., \& Peters, G. (2000). Governance, Politics, and the State. St. Martin's Press.

Poocharoen, O., \& Ting, B. (2015). Collaboration, co-production, networks: Convergence of theories. Public Management Review, 17(4), 587-614. https://doi.org/10.1080/14719037.2013.866479

Rhodes, R. A. W. (1994). The hollowing out of the state: The changing nature of the public service in Britain. The Political Quarterly, 65(2), 138-151. https://doi.org/10.1111/j.1467-923X.1994.tb00441.x

Rhodes, R. A. W. (1996). The new governance: Governing without government. Political Studies, 44(4), 652-657. https://doi.org/10.1111\%2Fj.1467-9248.1996.tb01747.x

Rhodes, R.A.W. (1997). Understanding governance: Policy networks, governance, reflexivity and accountability. US. Open University.

Rhodes, R. A. W. (2000). Governance and public administration. Oxford University Press.

Salamon, L. M. (Ed.). (2002). The tools of government: A guide to the new governance. Oxford University Press.

Stel, N., \& Abate, F. M. (2014). Between control and cooperation: Multi-stakeholder service provision and the legitimacy of state institutions in Ethiopia's Amhara National Regional State. European Journal of Development Research, 26(5), 743-760. https://doi.org/10.1057/ejdr.2013.60

Sørensen, E., \& Torfing, J. (2005). Network governance and post-liberal democracy. Administrative Theory \& Praxis, 27( 2), 197-237. https://doi.org/10.1080/10841806.2005.11029489

Sørensen, E., \& Torfing, J. (2007). Theories of Democratic Network Governance. Palgrave Macmillan.

Stoker, G. (1998). Governance as theory: Five propositions. International Social Science Journal, 50(155), 17-28. https://doi.org/10.1111/1468-2451.00106

Sullivan, H., and Skelcher, C. (2002). Working across boundaries: Collaboration in public service. Palgrave Macmillan. https://doi.org/10.1007/978-1-4039-4010-0

Zammit, A. (2003). Development at risk: rethinking UN-business partnerships. South Centre and UNRISD. 